\title{
Translator's Horizon of Expectations and the Inevitability of Retranslation of Literary Works
}

\author{
Jinfeng Zhang \\ Qingdao University of Science and Technology, Qingdao, Shandong Province, China
}

\begin{abstract}
Horizon of expectations, as a core concept in Reception Aesthetics, provides a new methodological basis for literary translation. Owing to this theory, literary translation is no longer a one-way process which is text-centered and transmitted by a translator with readers passively accepting everything, but an ever-going dialogic process between translator and the literary work, and between translator and implied readers, which results in the necessity, possibility and even sometimes inevitability of retranslation of literary works. Horizons of expectations widen people's space of cognition for retranslation of literary works.
\end{abstract}

Index Terms - horizon of expectations, literary translation, translator, inevitability of retranslation

\section{THE DEFINITION OF RETRANSLATION OF LITERARY WORKS}

Literary translation first appeared as an independent concept in western translation theories. Most westerners tended to treat literary translation as creation of literary work of art. They refer to literary translation as the translation of literary works (novels, short stories, plays, poems, etc.). If the translation of non-literary works is regarded as a skill, the translation of fiction and poetry is much more of an art. Many consider some forms of poetry to be almost impossible to translate accurately, given the difficulty in rendering both the form and the content in the target language.

Considering the artistic, creative characteristics of literary translation, retranslation of literary works can be then defined as: Retranslation of literary works, in practice, is the translator's attempts to further explore the artistic value of the original work (including the form, style, meaning, image, culture, etc). In fact, it is the result of inadequate dialogue between the author of the original literary text and the translator, between the translator and his implied readers, between past and present. Historicity and subjectivity of the three entities---the author, the translator and the implied readers, are the major factors which influence the forms of TL texts. To reach the real meaning of the SL text and to meet his implied readers' need, a translator, at his work, tries to compromise with both sides but his translation is merely a perfect one provisionally because everything changes with the time going on. Every attempt to explain the original text produces a new translation, which is retranslation.

This definition points out two causes to the retranslation of literary works: firstly, inadequate dialogue; secondly, historicity and subjectivity of three entities in translation. Retranslation of literary works has become a more and more common phenomenon in our society, but what is the real reason behind it? The two causes mentioned above are not systematic theories or ideas. With regard to this deficiency, I tentatively utilize horizon of expectations as the theoretical basis to attract people's attention from practical activities to theoretical arguments.

\section{The MATURATION OF HorizOn OF EXPECTATIONS}

In the 1960s, on the basis of phenomenology and hermeneutics, Constance School, represented by Hans Robert Jauss and Wolfgang Iser, established "reader-centered" Reception Aesthetics, which aimed at readers' reception in the literary work (Hu \& Wang, 2001). As the core concept of Reception Theory, Horizon of Expectations refers to the set of expectations against which readers perceive the text. It claims that people within the culture share a common set of understandings about what's possible, probable, impossible, etc. ${ }^{1}$ It is our shared "horizon of expectations" that make our mutual understanding possible, and even people out of different cultures can communicate with each other because they have the similar horizon of expectations for the same thing though they use different languages. How to express distance is a case in point. Though English-speaking people apply "meter" while Chinese people employ "mi", they show no difference in communication because both "meter" and "mi" are the measurement of units shared within people's horizon of expectations, with the help of which, it is easy to translate one into the other. Owing to horizon of expectations, people of different languages can communicate easily. However, horizon of expectations does not always play a positive role in communication. Sometimes it may block people's understanding and even result in misunderstandings.

There are mainly two kinds of "horizon of expectations": firstly, the narrow horizon of experience, the horizon of literary expectation, which includes presumed artistic or literary norms and conventions of a particular period. It is related to genre, style, and form of the literary texts; while secondly, the wide horizon of experience, the horizon of

\footnotetext{
${ }^{1}$ http://faculty.goucher.edu/eng211/readerresponse_theory.htm
} 
experience of everyday life, includes the assumptions of the whole socio-cultural world of a community or of an individual, whether as the author, the initial reader or the later reader. People out of different periods and experiences will have different horizon of expectations, no matter it is the literary horizon or the wide one.

Jauss further distinguishes three basic experiences: a productive aesthetic praxis, a receptive praxis, and a communicative praxis, and he claims that a detailed study of these three elements can help literary history steer a course between an exclusively aesthetic and an exclusively sociological perspective. The most important one for Jauss is the third, communicative aesthetic praxis, which is defined as the "enjoyment of the affects as stirred by speech or poetry which can bring about both a change in belief and the liberation of his mind in the listener or the spectator" (Jauss, 1982). When readers reads a work, their horizons can arouse their previous experiences, bring a certain feeling to them, and make them have various expectations for the work's development and the end.

\section{The Close RelationshiP BETWEEN HORIZON OF EXPECTATIONS AND RETRANSLATION OF LiTERARY WORKS}

A reader's understanding cannot escape from the constraints of historicity which refers to the historical society he lives in or the reader's own previous experiences. A literary work can be regarded as special history with its own relations to general history. "It is not a monument that mono-logically reveals its timeless essence. Probably it satisfies, surpasses, disappoints, or refutes the expectations of its first audience. A literary work does not offer the same view to each reader in each period that makes possible its ongoing, developing meaning; a literary work may evoke certain expectations of a reader which are then varied, corrected, altered or even just reproduced in the course of reading" (Jauss, 1967). A literary work calls for the participation of reader's horizon of expectations. Literary translation, in which translators do readings and interpretations, surely cannot be realized without the participation of translator's expectations, which, are continuously modified and changed over time and bear great personal distinctions. The updated horizons are of slight or great difference and will be able to guide perceptual exploration more efficiently in the future. That is, horizons are both historically restricted and subjectively confined. Historicity and subjectivity should be the basic characters of horizons.

Undoubtedly, there should be a certain connection between horizons and retranslation of literary works because both of them have historical and subjective characters. Rather than evaluate different TL texts, this paper tends to prove the possibility, acceptability and inevitability of retranslation of literary works microscopically, especially in terms of the roles translators play in the translation process.

\section{The CONTRibution of Translators' Horizon of EXPECTATION TO Literary RETRANSLATION}

A translator at his work is guided by horizons of expectations from three sides: the original author's horizons, his own horizons and the implied readers' aesthetic expectations. Ideal translation should be the successful dialogic process and result between the horizons of these three entities.

In translation, "the translator stands at the centre of this dynamic process of communication, as a mediator between the producer of SL text and whoever are its TL receivers. The translator is first and foremost a mediator between two parties for whom mutual communication might otherwise be problematic" (Hatim \& Mason, 1990: 223). Therefore, we cannot ignore the translator's mediator status---firstly as the reader of SL text; secondly as the producer of TL text. These two identities determine that a translator mainly has two jobs: firstly reading, then interpretation. Through him, the mediator, two different languages and cultural norms negotiate. The translation, virtually, should include the negotiation activity and process, not merely is a product which aims at conveying the meaning of an original message of SL text to readers across language and culture (Xu, 2004). The translator's mental conception of the SL text is important for his production of TL text.

The translator's role in literary translation shows that he is an actively independent agent. Out of different experiences as well as different cultural backgrounds, different translators have different horizons which will affect the their mental conception of the SL text---Textx proposed by Ma Xiao who says Textx is an invisible variable in translator's mind that changes with different translators who participate in the communications as well as changes in time and space (Ma, 2000). It is common for translators to exert their imagination and creativity to interpret a SL text. Textx is the translator's mental production before he creates the TL text. However, their different horizons affect their Textxs which cause their different interpretations for the SL text.

\begin{tabular}{|c|c|c|c|}
\hline \multirow{2}{*}{$\begin{array}{l}\text { Author's } \\
\text { horizons }\end{array}$} & Reflect & \multirow{2}{*}{ SL Text } & \multirow[t]{2}{*}{ Enter } \\
\hline & & & \\
\hline
\end{tabular}

Gadamer has said, "No translation can replace the original work. The translator's task is never to copy what is said, but to place himself in the direction of what is said (i.e. in its meaning) in order to carry over what is to be said into the direction of his own saying" (Newmark, 2001: 79). This means different translators out of different horizons have the rights to make different understandings and interpretations of a same work. Surely, the different interpretations come up with different TL texts. Because of the influence of translator's horizons, retranslation is inevitable. 


\section{A. Historicity of the Translator's Horizons of Expectations}

According to hermeneutics, every translator is a finite, historical being with a history he can never get rid of. As a human being living in society, he has various connections with the social and historical context. He cannot avoid explaining the language, culture, society and history of foreign countries from his own cultural background, no matter how strong critical consciousness he has, he cannot completely deviate from the restrictions of his unconsciousness (Zhang, 2002).

The potential meaning of a literary work cannot be fully recognized by a particular reader or readers of particular time. It is gradually unfolded through constant chain of readers' reception. No reader can come to a vantage point outside the course of history and surpass all the previous readers and stay away from their objective influences. In translation, a translator, as the reader of SL text, cannot come to a vantage point outside the course of history to fully recognize the potential meaning of the work. The historicity of his horizons restricts his understanding. Every one who reads an original text tries his best to get the meaning of the text, but ends up by getting only some parts of the meaning. No one can confidently claim that he has got all of the meaning of the text. With the development of culture, succeeding translators may be able to discover features and implications of an original text which previous translators neglected or distorted.

Proper study of any narrative, Jauss argues, involves a reconstruction of the horizon of expectations of its original audience. Narratives should not be seen as reflections of a historical moment, or imitations of "reality", but as actually intervening in historical struggle, and perhaps changing people's perceptions of the world in which they live.

A translator in translation, his role as the reader is somewhat the same as the original audience mentioned by Jauss. However, compared with the author and the original audience of the literary work, he is generally living in different periods or different cultures, owing to which, his horizons are of difference because any horizon is a historical one. Therefore, a translator's understanding of the work actually is not the mere reflection of the author's historical horizons, or imitation of the SL text "reality", but is the combination between his horizons which are historically controlled and the author's expectations which reflect the historical features of the author's period.

The historicity of horizons predestines any version is a historical one which can only satisfy its contemporary readers' needs. When history steps into a new period, the translator's present horizons changes, and the dialogue between original author's horizons and those of the translator alters as well. New horizons yield new dialogue which provides more likelihood to the new interpretation of the SL text. That is retranslation. Here, one sentence in Gone with the Wind can be taken as an example:

SL sentence: Seated with Stuart and Brent Tarleton on the cool shade of the porch of Tara, her father's plantation, that bright April afternoon of 1861, she made a pretty picture. (Margaret Mitchell, 1998)

Translation Version I: 一八六一年四月一个晴朗的下午, 思嘉小姐在陶乐垦殖场的住宅, 陪着汤加那一对双胞 胎兄弟———个叫汤司徒, 一个叫汤伯伦一一坐在一个阴凉的走廊里。这时春意正浓, 景物如秀, 她也显得格 外标志。( Fu, 1979)

Translation Version II: 一八六一年四月一个晴朗的下午, 思嘉同塔尔顿家的孪生兄弟斯图尔特和布伦特坐在他 父亲的塔拉农场阴凉的走廊里，她标致的模样儿使四周的一派春光显得更明媚如画了。（Dai, 2003）

Firstly Gone with the Wind was treated as a love story, in which characters are the most important part. Therefore, in Version I, Fu Donghua employed the dashes to emphasize the name of Stuart and Brent Tarleton, and also drew on the idioms like “春意正浓”, “景物如秀”to present the beautiful pictures to his readers. But with time going on, people realized that this work was more like the description of American civil war and they wanted to see the real story. Then, the succeeding translators' translations became more objective. In Dai Kan's version, this sentence was translated with more objective features.

Literary work, which stands for the development of a country's language, culture, thought, politics, etc, bears great historical features rather than is just a passive reflection of the real world. Translators' changing horizons directly influence their understandings of the work. Even the same translator may have different understandings while rereads the work. Historically situated translators with historically restricted horizons create diverse interpretations which are filled with historical features. New era requires new interpretations which can reflect its characters. At this time, it is necessary for translators to make new TL texts.

\section{B. Subjectivity of the Translator's Horizons of Expectations}

A Translator with different knowledge structure, psychology structure, properties, aesthetic values and appreciation tendency, namely his horizons are rather changeful and full of subjectivities. It is evident that he will be actively involved in the translation process, but not passively making copies of the original work. He is easily influenced by his respective horizons and thereby holds different translation purposes or strategies. "The interpretation of the SL text is one of the linguistic activities which are not only the means to manifest oneself and the reflection of one's own specific view of the world, but also the reflection of one's mental activities" (Tu, 1996: 587). As a mental activity, a translator's interpretation of the SL text of course bears great subjective features which are usually influenced by his horizons.

In contrast to the author-centered and text-centered theorists who believe the meaning of a literary text have already existed before the act of reading, Jauss provides more freedom to readers. For Jauss, a frequently neglected element of 
the meaning of any narrative is their audiences, who already have experience in consuming other narratives.

A literary work, even if it seems new, does not appear as something absolutely new in an informational vacuum, but predisposes its readers to a very definite type of reception by textual strategies, overt and covert signals, familiar characteristics or implicit allusions. It awakens memories of the familiar, stirs particular emotions in the reader and with its 'beginning' arouses expectations for the 'middle and end', which can then be continued intact, changed, reoriented or even ironically fulfilled in the course of reading according to certain rules of the genre or type of text. ...The new text evokes for the reader (listener) the horizon of expectations and rules familiar from earlier texts, which are then varied, corrected, changed or just reproduced. Variation and correction determine the scope, alteration and reproduction of the borders and structure of the genre.

As a reader of SL text, a translator has his own familiar memories or particular emotions which arouse his different assumptions or expectations for the "middle and end" of the literary work. He brings to the work his own assumptions based on previous experiences of the world, which influence his understanding of each successive portion of the work and about the likely development of the text.

In the process of literary translation, what a translator faces is the SL text with artistic characters resulting from the author's historical and subjective horizons. When reading the SL text, the translator is having a dialogue with the author. The translation process is the ever-going dialogue between the two entities---author and translator. "Reading is a two-way process. For one thing, readers bring to texts their own sets of assumptions based on previous experience of the world, so that each successive portion of text is processed in the light of these assumptions, and predictions are made about the likely development of the text. For another, text items are analyzed in themselves and matched against each other, a process of syntactic and lexical decoding which results in the gradual building up of composite meaning as reading proceeds" (Hatim \& Mason, 1990: 226).

$\mathrm{Xu}$ Jun says as an aesthetic agent, the translator obviously will be constrained by various factors, such as his own interests, needs, knowledge, experience, appreciation of literature, habit, even his individual beliefs. All of these factors make his understanding as well as interpretation bear subjective characters (Xu, 2003). The subjectivities of the translator's horizons result in his subjective understanding of the work which yields subjective interpretations of the work. In other words, translator can only understand those particular ones which have already existed in his mind. Any understanding depends on his depth of experience. That is why translations always remain to some extent irrational and subjective.

For example, Hong Lou Meng, as a great work, has several translated versions, among which A Dream of Red Mansions by Yang Xianyi and Dai Naidie, and The Story of the Stone translated by David Hawks are the most influential. Hawks, though seemed to know everything about China, could not understand all the images of Chinese culture, especially some particular ones. His translation reflected his expectations for the culture, language of this book and there existed many subjective interpretations. Here, I not want to judge which one is better by comparing the two translated versions; instead, I just propose some simple examples to illustrate that the subjectivity of the translator's horizons cannot be neglected. To approach the real meaning of the SL text, succeeding translators should and must retranslate the work time and again.

“潇湘馆', the place with a lot of bamboos in Cao Xueqin's work, is translated into 'the Naiad's House' by Hawks. Naiad, a fairy living by the river in Achaean fiction, never means bamboo in English. Therefore, Hawks' translation is not suitable. On the contrary, Yang Xianyi's 'Bamboo Lodge' is much better. Translator's horizons, which are restricted by his education, culture, habits and so on, cannot avoid the subjectivity that will influence translator's understanding and interpretations of the work, sometimes even resulting in misunderstandings. In western culture, being a plant, bamboo means nothing to them, whereas in China, it stands for a fortitudinous character. Hawks will never have the same feeling as we have. Thus, it is impossible for him to understand the connotative meaning of bamboos" (Zhang, 2002: 48). Here, retranslation should be done for the sake of correcting misunderstandings.

Another example, “世上只有神仙好, 惟有功名忘不了', Hawks translation was 'Men all know that salvation should be won.' In his version, “神仙' was translated into 'salvation' which means “拯救” in Chinese. It is a word in Bible, means deliverance from the power or penalty of sin. However, “神仙'which means free from death, is a word used in Taoism in our culture” (Zhang, 2002: 49). Hawks must know the denotation of “神仙”, but deeply influenced by Bible, he cannot escape from misunderstanding it as something like deliverance from the power or penalty of sin in the Bible.

Every translation has its advantages and disadvantages because the subjectivity of horizons does not always perform a negative role in translation. The author of the SL text just finishes the form or the structure of the literary work. It is the translators' turn to make it flourishing. Hamlet, the famous tragedy of Shakespeare, with translators' active participations, presents a more and more vivid world to its readers. The form of the work is in 16th century's style, but with the unceasing dialogue between succeeding translators' horizons and those of the author, the work's life is always full of new blood which attracts different readers out of different periods or backgrounds. Without the subjectivity of translators' horizons, I do not think Shakespeare's work can come down to us from 16th century.

Compared with idea, which is the key point of culture transmission, language is just a tool. Ideas change all the time which lead to the change of horizons. Therefore, retranslation, not only is the reconstruction of language, but also is the reconstruction of ideas. New ideas generate new horizons which influence translator's translation strategies. Generally 
speaking, the more understanding of the original work, the further concretization they do. Retranslation, hereby, is unavoidable.

\section{REFERENCES}

[1] Daikan, Li Yeguang \& Zhuang Yichuan (Trans). (2003). Gone with the Wind. Beijing: Foreign Literature Press.

[2] Fu Donghua (Trans). (1979). Gone with the Wind. Huangzhou: Zhejiang Literature and Art Press.

[3] Hatim, B. \& I. Mason. (1990). Discourse and the Translator. London: Longman Inc.

[4] http://faculty.goucher.edu/eng211/readerresponse_theory.htm (accessed 20/2/2013).

[5] Hu Jingzhi \& Wang Yuechuan. (2001). Aesthetic Methodology. Beijing: Peking University Press.

[6] Jauss, Hans Robert. (1967). Literary History as a Challenge to Literary Theory. Trans. Elizabeth Benzinger. New Literary History 2, 206-209.

[7] Jauss, Hans Robert. (1982). Toward an Aesthetic of Reception. Trans. Timothy Bahti. Minneapolis: University of Minnesota Press.

[8] Ma Xiao. (2000). Aesthetics of Reception in Literature Translation. Chinese Translators Journal, 2. 47-51.

[9] Mitchell, Margaret. (1998). Gone with the Wind. New York: Oxford University Press.

[10] Tu Jiliang. (1996). Comparison Study of Modern Language Philosophy. Beijing: China Social Sciences Press.

[11] Xu Jun. (2003). Inter-Subjectivity and the Fusion of Horizons in Translation. Foreign Langage Teaching and Research, 4. 290295.

[12] Xu Yujuan. (2004). Reception Theory and Re-creation in Literary Translation. Master dissertation. Nanjing Normal University.

[13] Zhang Yingxian. (2002). Creative Imagination and Creative Variability of Image in A Dream of Red Mansions. Foreign Languages and Their Teaching, 47-50.

Jinfeng Zhang was born in Qingdao, Shandong Province, China in 1980. She received her M.A. degree in Foreign Linguistics and Applied Linguistics from Ocean University of China, China, in 2005.

She is currently a lecturer in the School of Foreign Languages, Qingdao University of Science and Technology, Qingdao, China. Her research interests include literary translation and retranslation. 